\title{
MY FAVOURITE SENTIENCE
}

\author{
Something to watch over me.
}

\section{BY MARISSA LINGEN}

$\int$ essa, age 9. Yorknet is my favourite sentience because it is dependable, protective and wise. Yorknet is dependable because there are several back-ups, so that if one system goes down, the sentience is mirrored in several other places, my mam says. This makes Yorknet more dependable than a human whose brain is only in one place. Yorknet is protective because it watches all our personal information like money and health stuff so no one can steal it. Yorknet is wise because it tells us what to do for school, work, home and hobbies. It knows because it has looked at our personal information. Yorknet takes care of us all. Yorknet is my favourite sentience for these good reasons.

Ruby, age 8. I like the uplifted yellow meranti tree colony in Terengganu. I think it is the kindest sentience, and that is why it is my favourite. It does not hurry anybody along but lets us all go at our own pace. My granddad took me to see the uplifted yellow meranti colony when we went to Malaysia together last summer, and we spent all day wandering among the trunks and talking to it and listening to the wind in its branches. Also, the uplifted yellow meranti colony is quite interested in turtles and spiders and other things like that and so am I. I think we should pay more attention to the sentiences that are not focused on humans.

Freddie, age 9. My favourite sentience is the Fourierist human collective in Doubs. They use WiFi to string all their brains together, which I think is neat because it's like one person thinking but all of them and so if you can't figure out your sums it's not cheating because it's everybody's sums, so you could get Jessa to do it while you did something else. Lots of people have strung together several computer chips at once to make a sentience for ages and ages. Which is very nice, I'm sure, but the Fou-

$\rightarrow$ NATURE.COM Follow Futures:

@ @NatureFutures

f go.nature.com/mtoodm rierists now do it with people too, which is cool and modern not like the old-fashioned way. That is why I like the Fourierists and I expect we should do one here in York any minute now. I would join up. Except my dad says we are not joiners in this family so probably we would have to discuss it, which means have a good yell.

would have hit him because we would still have had cars or perhaps a train would. Anyone who picks another favourite sentence than Yorknet is dumb and wrong.

Amal, age 8. The squid hegemony in the Marianas Trench is a very interesting sentience that doesn't get enough attention, perhaps because vertebrates tend to be interested in our own kind. They are caretaking other sentiences in the region and also in the seas above them, in a $3 \mathrm{D}$ way that is very cool, I think. Also, they have good tentacles that I like. Also, the Marianas Trench covers more area and more volume than any other sentience rules so technically they are the biggest sentience on the planet. Also, the thing they do with the old lights and the plastic we thought was waste is amazing.

Bei, age 9. I think you will find that the sentience inside a house still counts. And I think we should count them. They are very small sentiences, but I like my house. My house is very attentive to small needs and never forgets a birthday or what goes on the grocery list. When we run out of apples my house reminds all our devices. I would have lost

Mo, age 9. The best sentience is Aixnet because it is the most glamorous of all the citynets. No offence to Yorknet, which I'm sure is very nice, but Aixnet has a sense of style and flair that the other cities just have not managed. Aixnet does not just coordinate and protect its citizens, it has an instantly recognizable brand and jingle that no other city can match. Aixnet is so pretty. We should all consider helping other sentiences to be a bit more like Aixnet and the world would be a nicer place to live.

Brian, age 10. Yorknet is the greatest of all the sentences ever and everyone knows it. My dog ran away and Yorknet found it and we didn't have to worry because Yorknet knew where my dog was. He would have slept out alone in the old days. Who knows where he would have gone. He is the best dog and his name is Orville and I have taught him to put his nose in my sister's bum, which makes her yell. Without Yorknet maybe a car my science-fair project last year if my house had not reminded me to take it. My house is a lot like Yorknet but more personal, so it is my personal favourite sentience.

Riley, age 9. My mam is my favourite sentience. This does not make me a mummy's boy, no matter what Brian says. Unlike many other sentiences, including Yorknet, my mam has never destroyed a city. Except for South Tyneside and that was an accident. The other sentiences are not as warm as my mam and do not play football like my mam and in general are less fun. But they do make you go to bed on time just like my mam if Yorknet is any indication, so really, on the whole, my mam is the best sentience because she has the same down sides as the other ones but her good points are nicer.

Marissa Lingen has published more than 100 short stories in venues such as Analog, Lightspeed and Tor.com. 